\title{
An Acidic Esophagus!
}

\section{(1) Satvinder Singh Bakshi}

All India Institute of Medical Sciences Mangalagiri, Mangalagiri, India

Keywords: Corrosive acid, Endoscopy, Dysphagia

\section{Case Description}

A 19-year-old female presented with odynophagia and a burning sensation in the mouth for 2 hours. She had deliberately taken a mild amount of dilute hydrochloric acid due to suicidal intention. On examination, she had diffuse erosions and edema on her oropharynx; upper gastrointestinal endoscopy was done after 24 hours revealed multiple erosions and slough throughout her esophagus (Figure 1a and 1b). She was started on proton pump inhibitors, steroids and broad-spectrum antibiotics; in addition, a nasogastric tube was inserted under endoscopic guidance. Her hospital stay was uneventful, and a repeat endoscopy in 2 months follow-up revealed only minimal strictures.

Ingestion of corrosive substances (alkalis or acids) is mostly accidental in children compared to adults, where it is usually suicidal (1). In western countries, alkaline material is common, whereas injuries from acid are more common in developing countries, likely due to easy accessibility to acids like sulfuric acid (2). Acids cause coagulation necrosis, leading to eschar formation, limiting penetration and injury depth (1). The type of the substance, amount, physical form and time of presentation determine the clinical picture. Dysphagia and odynophagia are seen due to oropharyngeal or esophageal involvement; hoarseness and stridor occur due to laryngeal or epiglottic damage, presence of epigastric pain and hematemesis are more common in stomach involvement (3). Worsening of abdominal pain or development of chest pain implies a perforation. Laboratory tests that predict poor prognosis are a high white blood cell count, elevated serum C-reactive protein and arterial $\mathrm{pH}$ less than 7.22 (1-3). Upper gastrointestinal endoscopy to determine the extent of damage is recommended in the first 12$48 \mathrm{~h}$ after caustic ingestion. Contraindications to endoscopy are suspicion of perforation or supraglottic or epiglottic burns with edema (3). A CT scan is valuable in these patients and offers a more detailed evaluation of the transmural damage of esophageal and gastric walls (2). The initial priority in management is airway and hemodynamic stability. Gastric lavage and induced emesis are contraindicated as it causes re-exposure to the corrosive agent (3). Nasogastric tubes under guidance can be inserted as a stent in severe circumferential burns. Proton pump inhibitors and steroids are started in order to prevent stricture formation. In addition, broad-spectrum antibiotics are started when steroids are initiated or when pulmonary involvement is seen.

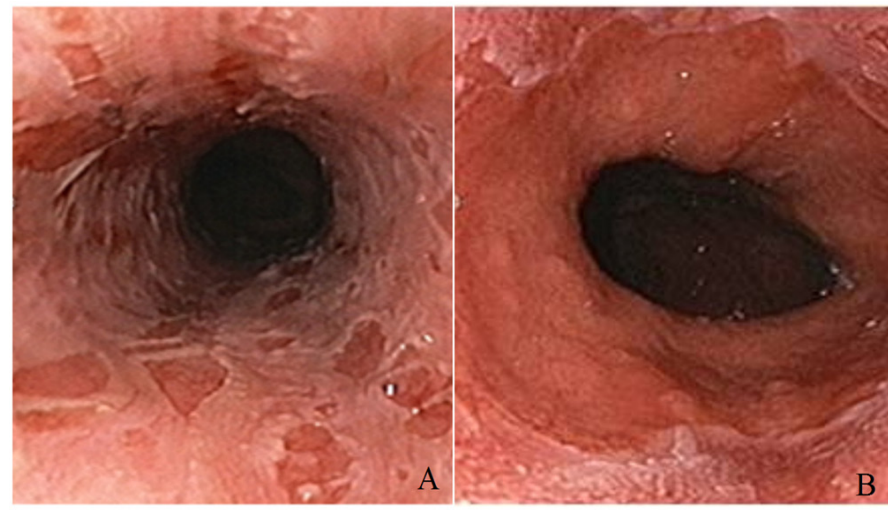

Figure 1. a-b. Endoscopic view of the esophagus showing diffuse erosions and edema throughout the esophagus 


\section{Conclusion}

Patients with evidence of perforation require urgent surgical intervention such as laparotomy, esophagectomy, gastrectomy or jejunostomy feeding $(2,3)$. The most common delayed sequel is stricture formation others are intractable pain, gastric outlet obstruction, late achlorhydria, protein-losing gastroenteropathy, mucosal metaplasia and development of carcinoma (4).

\section{Ethics}

Informed Consent: Informed consent was obtained from the patient.

Peer-review: Externally peer-reviewed.

Financial Disclosure: The authors declared that this study received no financial support.

\section{References}

1. Robustelli U, Bellotti R, Scardi F, Fortunato Armellino M, De Masi A, Forner $\mathrm{AL}$, et al. Management of corrosive injuries of the upper gastrointestinal tract. Our experience in 58 patients. G Chir. 2011;32:188-93.

2. Rajabi MT, Maddah G, Bagheri R, Mehrabi M, Shabahang H, Lorestani F. Corrosive injury of the upper gastrointestinal tract: review of surgical management and outcome in 14 adult cases. Iran J Otorhinolaryngol. 2015;27:15-21

3. Javed A, Pal S, Krishnan EK, Sahni P, Chattopadhyay TK. Surgical management and outcomes of severe gastrointestinal injuries due to corrosive ingestion. World J Gastrointest Surg. 2012;4:121-5.

4. 4Kochhar R, Sethy PK, Kochhar S, Nagi B, Gupta NM. Corrosive induced carcinoma of esophagus: report of three patients and review of literature. J Gastroenterol Hepatol. 2006;21:777-80. 